\title{
Efecto de la web 2.0 en el desarrollo de emprendimientos
}

\section{Effect of web 2.0 on the development of ventures}

Méndez Bravo, J. C.

Universidad de Guayaquil, Ecuador

Universidad Internacional del Ecuador, Ecuador

Palacios Sarmiento T. Y.

Universidad Internacional del Ecuador, Ecuador

Méndez Bravo, M. A.

Universidad de Guayaquil, Ecuador

Autor corresponsal: julio.mendezb@ug.edu.ec, tapalaciossa@uide.edu.ec, manuel.mendezb@ug.edu.ec

Fecha de recepción: 30 de Septiembre de 2017 - Fecha de aceptación: 15 de Abril de 2018

\section{Resumen}

La era tecnológica ha influido el mundo real (off line) y la web 2.0 permite la interacción a todas las personas generando cambios significativos para el emprendedor entorno al Internet que se ha vuelto una importante plataforma en la actualidad. Esta abarca medios como los wikis, redes sociales utilizadas para la publicidad a nivel empresarial, Crowdfunding que es la búsqueda de recursos para proyectos usando plataformas online, Enterprise 2.0 que trata del desarrollo de una empresa en internet. El paper analiza las diferentes formas de generar emprendimientos mediantes medios informáticos e internet.

Palabras Claves: web 2.0; wikis; redes sociales; crowdfunding; enterprise 2.0

\begin{abstract}
The technological era has influenced the real world (off line) and web 2.0 allows interaction to all people generating significant changes for the entrepreneur around the Internet that has become an important platform today. This covers media such as wikis, social networks used for advertising at the business level, Crowdfunding that is the search for resources for projects using online platforms, Enterprise 2.0 that deals with the development of a company on the Internet. The paper analyzes the different ways of generating enterprises through media and internet.
\end{abstract}

Key words: web 2.0; wikis; social networks; crowdfunding; enterprise 2.0 


\section{Introducción}

Como lo indica Venkataraman (1997) citado por Njegomirl, Tepavac, \& Ivanisevic (2017) el: "Emprendimiento proporciona respuestas a las preguntas de cómo, por quién y con lo que se detectan, crean y explotan las oportunidades para la introducción de nuevos productos y servicios." Y un factor de gran importancia para que los emprendimientos tomen más tiempo del que necesita o no se ejecuten, es la falta o escasa financiación, por lo que en la web 2.0 hemos hallado un financiamiento alternativo. Por lo cual el paper está estructurado de la siguiente manera, primero se analiza de manera conceptual en que consiste la web 1.0 y la versión 2.0. Como explica Alarcon del Amo, Romero, Gomez Borja, \& Mondéjar Jiménez (2012): "La Web se ha convertido en la fuente de información principal cliente sobre productos y servicios para muchos de sus usuarios."

La primera versión de la web Becerril, y otros (2012) la define como el: "Uso de páginas web estáticas que no permiten, en su generalidad, la participación de los usuarios en su elaboración. Consoli (2012) hace referencia a la segunda evolución de la web como una revolución en lo que concierne la generación de contenidos, en la cual el propio usuario es quien puede generar contenidos, películas, opiniones y demás, dando como resultado el contenido generado por el o también como consumidor del contenido proporcionado.

Dada toda esta revolución causada por el internet y la web 2.0 se comenzaron a desarrollar nuevas terminología una de ellas llamadas redes sociales quien Estevez \& Garcia (2014) las define como: Una herramienta de enorme potencial dentro de un conjunto de aplicaciones diversas. Dentro de una sociedad globalizada y de la información como la actual, en la que se puede acceder a contenidos digitales desde cualquier terminal con acceso a Internet: móvil, tableta, portátil.

$\mathrm{Y}$ otras que hacen referencia a una fuente de financiamiento alternativo para desarrollar proyectos por parte de emprendedores y nace el Crowdfunding, esto abarca la segunda parte del paper. La cual Gomez de la Rosa (2015) lo define como: Un fenómeno enmarcado dentro de los nuevos movimientos colaborativos en los que un conjunto de individuos realiza pequeñas aportaciones a una causa u objetivo y pese a que la aportación individual puede ser insignificante, un gran número de participantes, el Crowd, hace que en su totalidad la contribución sea relevante.

Njegomirl, Tepavac, \& Ivanisevic (2017) opina que: "El Crowdfunding proporciona financiamiento barato y más rápido que los empresarios pueden ir directamente a los inversores, proveedores y clientes, mucho más bajas las tasas de interés que los de los bancos." Según los autores Schaefer \& Forbes (2017) afirma que este fenómeno ha conseguido una gran popularidad en el siglo XXI, dando como resultado un método viable en la financiación de proyectos para emprendedores.

Dentro de esta modalidad existen 4 tipos de crowd como las define Ruiz (s.f): el primero basado en donativos el cual se caracteriza por apoyar investigaciones, proyectos personales en la que los accionistas no esperan recibir ningún tipo de beneficio económico, el segundo basado en recompensa, en la cual los inversionistas otorgan un beneficio económico al proyecto con el fin de obtener algo a cambio como por ejemplo un producto o servicio, el tercero basado en crédito 
como su nombre lo indica cada acreedor designa aporta una cantidad monetaria al proyecto en la cual este se convierte como un préstamo hacia el promotor del proyecto o empresa y por ultimo tenemos el basado en acciones, se define como la contribución de un número determinado de acciones a los inversionista todo esto llevado a cabo mediante un contrato. Como desarrollador de un proyecto se deben tener en consideración estas 4 modalidades al momento de usar este medio como fuente de recursos económicos.

Además se proporciona una serie de pasos la cual debe seguir el emprendedor para usar el crowdfunding en su proyecto dentro de una plataforma dedicada a esta actividad, se hace mención algunas de plataformas existen a nivel Latinoamericano, y los riesgos que se conlleva dentro de estas.

La tercera parte consiste en la llamada Enterprise 2.0, según Consoli (2012) la define como un modelo para llevar a cabo negocios, donde tanto empresa como clientes trabajan de forma conjunta para mejorar le producto o servicio, llegándose a desarrollar lo que se conoce como Empresa 2.0, conceptualizándose como: "Una nueva compañía de avanzada que interactúa con todos los actores de la cadena de suministro y en particular con los clientes utilizando herramientas web 2.0 (blog, foro, chat, wiki) y redes sociales, caracterizándose por compartir colaboración, interactividad y agilidad." Consoli (2012)

Posterior se analiza cuáles son los riesgos tantos positivos y negativos de la web 2.0 con respecto a emprendimientos (Crowdfunding) y a nivel empresarial (Enterprise 2.0) y por último se da un claro ejemplo del éxito de un proyecto en una plataforma de Crowdfunding.

\section{Diferencias entre la Web 1.0 y la Web 2.0}

Antes que se desarrollase la web 2.0 que consiste en una evolución de la web 1.0 el cual marco precedente que era del internet. Becerril, y otros (2012) expone que: "En la web 1.0 las páginas web son estáticas y con poca participación de los usuarios en la elaboración de los contenidos, lo que hace que el uso de la web sea más pasivo que activo". Según Flores, Bertolotti, \& Gonzalez (2012) nos detalla que: "Mientras que en la Web 1.0 los usuarios son destinatarios de la tecnología, los contenidos y los negocios, en la Web 2.0 colaboran en el desarrollo de la tecnología mediante el software de fuentes abiertas, producen los contenidos y participan del negocio."

Como señala Rodriguez Diaz \& Gonzalez Rio (2016) la web 2.0 es una tecnología con un alto potencial de cambio, que a través de ella se logran modos de comunicación más eficientes entre empresas y clientes internos, consumidores (nivel de mercado) y con su entorno. Flores, Bertolotti, \& Gonzalez (2012) afirma: "En este contexto, la Web 2.0 multiplica las posibilidades de aprender al facilitar el acceso a todas las personas a través de múltiples dispositivos, permitiendo la participación activa de los usuarios, los cuales pueden compartir contenidos, experiencias y/o conocimientos". Como comenta Becerril, y otros (2012):

En la web 2.0 se establece el uso para mantener relaciones sociales de manera virtual, logrando con ello desaparecer las distancias y las limitantes del tiempo en estas relaciones, ejemplos de ello se encuentran en múltiples aplicaciones on-line tales como Facebook, Twitter, Hi5, etcétera. Es por esto que a la versión 2.0 se le llama la web social o colaborativa. Flores, 
Bertolotti, \& Gonzalez (2012) hace mención a esta plataforma, la cual tiene un valor principal que es la simplificación de lo que abarca la lectura y escritura dada de manera online, lo cual nos traduce a dos acciones sustantivas para el aprendizaje que es la generación de contenidos y compartirlos.

Como afirma Becerril, y otros (2012): "El principal valor que ofrecen las aplicaciones Web 2.0 es la simplificación de la lectura y escritura on-line.Esto se traduce en dos acciones sustantivas del proceso de aprendizaje: generar contenidos y compartirlos." Según Flores, Bertolotti, \& Gonzalez (2012) comenta que: "Web 2.0 abarca una amplia gama de tecnologías. Los más utilizados son los blogs, wikis, podcasts, información de marcado, los mercados de predicción, y las redes sociales." Becerril, y otros (2012) afirma que: En el nuevo modelo los usuarios son copartícipes en la generación y publicación de los contenidos de las páginas web; ejemplos de ello son los wikis, cuya aplicación más difundida se ilustra en Wikipedia. Un wiki permite que se escriban artículos colectivamente, co-autoría por medio de un lenguaje de wikitexto editado mediante un navegador. Una página wiki singular es llamada página wiki mientras que el conjunto de páginas, normalmente interconectadas mediante hipervínculos, es el wiki. Una característica que define la tecnología wiki es la facilidad con que las páginas pueden ser creadas y actualizadas y en general no hace falta revisión para que los cambios sean aceptados, la mayoría de wikis están abiertos al público sin la necesidad de registrar una cuenta de usuario.

Flores, Bertolotti, \& Gonzalez (2012) definen a las wikis como: Una de las herramientas de colaboración y participación de la Web 2.0, que permiten la generación y publicación de contenido fácilmente, este puede ser actualizado on-line por cualquier persona, miembro de un equipo de trabajo o una comunidad de aprendizaje, en cualquier momento, desde cualquier lugar con acceso a Internet, donde todos se encargan de la vigilancia y control del contenido publicado.

Flores, Bertolotti, \& Gonzalez (2012) comenta que estas wikis están diseñadas para lograr un trabajo en conjunto y la autoría de cada uno de los que participan dentro del mismo medio, mientras que los blogs son más a nivel personal, escritos por un solo autor." Estos mismos autores explican que: "Las wikis organizan la información en temas mientras que los blogs organizan la información en orden cronológico inverso."

\section{Terminologías desarrolladas en la Web 2.0}

Las economías contemporáneas basan esencialmente su crecimiento $\mathrm{y}$, de hecho, la viabilidad de su propio funcionamiento en la disponibilidad y el acceso al crédito en condiciones razonables. Dada esta intensa dependencia estructural, la paralización del crédito y un dramático recorte de las fuentes de financiación se perciben como efectos demoledores de la reciente situación de crisis económica y, a la vez, como detonantes de un agravamiento de sus consecuencias (Rodriguez De Las Heras Ballel, 2013).

\section{Crowdsourcing}

Galmes \& Borja Arjona (2012) se refiere que antes que se desarrollase el término Crowdfunding existía una terminología llamada Crowdsourcing basado en un concepto social como fuente de creatividad en contextos de crisis. Se dio por la unión de dos términos crowd que 
significaba multitud y outsourcing se definía como externalización o abastecimiento. En una primera aproximación conceptual, crowdsourcing se refiere al uso que las empresas o instituciones hacen de los colectivos como fuentes proveedoras de trabajo, recursos económicos o conocimientos e ideas (creatividad) (Galmes \& Borja Arjona, 2012).

Brabham (2008) citado por Galmes \& Borja Arjona (2012) opina que: “Todo proyecto crowdsourcing es difundido mediante convocatoria pública (call for proposals) a un amplio e indefinido grupo de personas."

El crowdsourcing nace, pues, de la "solicitud" o propuesta que una empresa o institución realiza a la comunidad, con el fin de fomentar su participación en un proceso determinado. El crowdsourcing puede ser una solución financiera para las empresas en el actual contexto de crisis económica, haciendo especial énfasis en compañías emergentes o sturtup. (Galmes \& Borja Arjona, 2012)

\section{Crowdfunding}

El Crowdfunding se deriva del concepto del crowdsourcing, que se define como una manera de aprovechar las soluciones creativas de una red de individuos con el fin de buscar solución a un problema (Ruiz, s.f). Según Pilar (2014) afirma que el nacimiento del fenómeno de CF se debe a varios factores: los avances tecnológicos son importantes, pero también lo es la participación social, así como la actual crisis financiera con las dificultades de endeudamiento que conlleva.

Ruiz opina que esta terminología tiene sus antecedentes en el año 1997 cuando una banda de rock consiguió financiar sus tours musicales a través de la ayuda que fue otorgada por sus fans en base a esto nace una plataforma en el año 2000 llamada AstitsShare en la ciudad de Estados Unidos siendo esta el primer medio para llevar acabo el Crowdfunding, la cual se dedicaba a la búsqueda de jóvenes que iniciaban su carrera musical. Este mismo autor define al Crowdfunding como un método de financiación que permite a las personas naturales invertir pequeñas cantidades de dinero en un proyecto determinado a través de un de una plataforma que se encarga de recolectar el dinero a cambio de obtener un beneficio económico o social, o incluso sin ánimo de lucro alguno.

Pilar (2014) lo conceptualiza en pocas palabras como la financiación de un proyecto o una empresa por un grupo de individuos en lugar de por profesionales. La misma autora expresa que el Crowdfunding se produce sin ningún intermediario: los empresarios "aprovechan la multitud", fondeando el dinero directamente de los individuos.

Ordanini, Miceli, Pizzetti, y Parasuraman (2011) citado por Ruiz (s.f) afirman que se identifican tres tipos de actores que se pueden diferenciar en un proyecto de Crowdfunding: el grupo que propone la idea o proyecto a financiar; los individuos que deciden apoyar estos proyectos aportando una cantidad de dinero; y las propias plataformas que facilitan la publicación del proyecto y la participación de las personas interesadas en apoyarlo.

Como da a conocer Belleflamme et al (2010); Burkett, (2011); Lambert y Schwienbacher (2010) citado por B. Bouncken, Komorek Lappeenranta, \& Kraus (2015) el Crowdfunding se 
puede dividir en Crowdfunding directo e indirecto. Crowdfunding directo se refiere a una solicitud de fondos directamente de recaudación de fondos a la multitud, por ejemplo, en el sitio web de la empresa. Crowdfunding indirecta implica un intermediario en el proceso de Crowdfunding como el recurso se anunció a través de una plataforma específica.

Rodríguez De Las Heras Ballel (2013) opina que el Crowdfunding crea valor porque consigue superar la simple emulación funcional de los modelos de financiación existentes y ofrecer otras funciones y herramientas estratégicas." Quero, \& Ventura (2014) citado en Ruiz (s.f) expone que el primer agente, o núcleo creativo, es el que promueve y diseña el proyecto de forma tal que permita atraer recursos financieros para poder llevarlo a cabo. Las plataformas aportan la tecnología necesaria para que se facilite la interacción entre los agentes principales y los agentes que financian la operación, su función principal es la de facilitar la difusión de la propuesta y que ésta tenga mayor alcance para lograr ser financiada. Las plataformas, además, presentan una continua asesoría en el diseño del proyecto y el acceso a diferentes medios de pago para los interesados en apoyar. Por su parte, los financiadores participan siguiendo diferentes motivos, es decir, existen desde individuos motivados únicamente por el deseo de ser parte de dicho proyecto, que aportan lo que corresponde a la pre-compra del producto, hasta agentes que aportan al proyecto con la finalidad de obtener un benéfico económico más allá del producto que hace parte del proyecto, un beneficio empresarial.

\section{Tipos de crowdfunding}

Dentro de esta plataforma existen tipos de Crowdfunding de las cuales se debe tomar en consideración al momento de elegir este método de financiamiento para proyectos en los cuales Rodriguez De Las Heras Ballel (2013) da a conocer las siguientes modalidades:

1. Donation-based crowdfunding.- Este modelo de Crowdfunding está dirigido a facilitar la recaudación de fondos para proyectos sociales. Se basa, por tanto, en aportaciones de usuarios en forma de donaciones para apoyar sin ánimo de lucro proyectos específicos de ayuda social liderados por organizaciones (generalmente, ONGs), asociaciones o individuos.

2. Reward-based crowdfunding.- En esta modalidad los usuarios contribuyen a la financiación de un proyecto específico con aportaciones económicas (de cuantía variable pero mayoritariamente reducida) a cambio de lo que genéricamente se denomina una "recompensa". Para que nos encontremos en esta modalidad de reward-based pura la recompensa no debe ser financiera.

3. Lending o debt-based Crowdfunding. - Esta modalidad de financiación en masa se construye sobre operaciones de préstamo entre el colectivo de usuarios (prestamistas) y los promotores del proyecto que buscan financiación. Esta categoría de Crowdfunding presenta diferentes formatos según la función desempeñada por el intermediario (gestor de la plataforma de Crowdfunding) y las condiciones económicas de los préstamos.

4. Equity-based crowdfunding o crowdinvesting.- El modelo del crowdinvesting consiste en la financiación en masa de proyectos mediante la participación en el capital de la sociedad promotora. Así, la contribución recibida se trata como aportación de capital y el aportante se convierte en socio o accionista de la sociedad promotora del proyecto, con el derecho a participar, en las condiciones legales y estatutarias, en los beneficios de la compañía o a recibir, de otro modo, parte de las ganancias del proyecto.

\section{¿Cómo obtener financiamiento dentro de una plataforma Crowdfunding?}


Ramírez Herrera \& Muñoz Campano (2016) nos da unos pasos para llevar a cabo este tipo de modalidad para los emprendedores y expone lo siguiente el Crowdlending goza de un funcionamiento muy simple ya que se trata de una plataforma virtual que, a través de una página web, pone en contacto a las dos partes principales del préstamo, es decir, a los prestatarios y a los prestamistas. El proceso para solicitar y obtener el crédito es el siguiente:

1. El prestatario accede a la plataforma web que desee y se registra para solicitar financiación. Debe realizar la correspondiente solicitud de préstamo indicando el nominal solicitado, el vencimiento y la finalidad propia del préstamo. Para ello habrá de aportar la documentación que la plataforma requiera, que habitualmente es muy similar a la solicitada por las entidades financieras tradicionales.

2. La plataforma web estudia la solicitud del préstamo y clasifica el riesgo de la operación mediante una aplicación de scoring predictivo. En caso de ser aprobado se comunica a través de la página web.

3. Una vez publicado el préstamo, los prestamistas (inversores) deciden si quieren participar y qué cantidad quieren aportar. Tres ello realizan dicha aportación económica (desde su cuenta virtual) por adelantado.

4. Si la operación alcanza el total del importe solicitado se formaliza el préstamo y el prestatario tendrá que pagar cada mes una cuota para devolver el préstamo más los intereses pactados. En caso de no conseguir el total solicitado el préstamo no se lleva a cabo y cada inversor recupera el dinero que previamente había aportado.

Como lo explica (Oh \& Baek, 2016) los factores más determinantes el éxito del Crowdfunding es que los emprendedores o desarrolladores de proyectos presten atención el comportamiento de la manada y realizar una correcta campaña, todo esto debido a la sobrecarga de información y la facilidad de observar el comportamiento de otros usuarios en línea.

\section{Plataformas de crowdfunding}

A nivel Latinoamérica se puede divisar algunas plataformas crowdfunding de gran éxito, entre las cuales el Foro de economía Digital (2015) citado por Ruiz (s.f) hace mención las siguientes:

- Kickstarter.- Es una plataforma que realiza el crowdfunding basado en recompensas siendo líder a nivel mundial, su éxito se debe que cualquier proyecto de algún emprendedor puede ser parte de la misma aunque esta no opere en el país natal del dueño del proyecto, pero se lo puede desarrollar por medio de sociedades norteamericanas.

- Indeogogo.- También es una plataforma basada en recompensa, pero su centro de actividad es financiar proyectos de teatro y cine independiente, su éxito es debido a que no limita la presentación de proyectos en lo que respecta el país de la empresa o persona que lo solicite.

- Ideame.- Es una plataforma de orígenes chileno que opera baja la característica de recompensas, su gran acogida que ha tenido a nivel d Latinoamérica son dos modelos que manejan: el modelo fijo que consiste en llegar alcanzar el 100\% del capital que se haya solicitado y el modelo flexible se caracteriza por otorgar todo el dinero recaudado hasta la fecha de cierre sin que haya alcanzado el $100 \%$.

- Fondedora.- tiene su origen en México y funciona bajo la misma modalidad que Ideame. 
- LaChévre.- es una plataforma de origen Colombiano que abarca mayor mercado en el financiamiento de proyectos como los de tecnología, diseño, editotial, arte, música, teatro, cine y video. Y ha adquirido el modelo flexible que maneja Ideame y Fondedora.

- Donaccion y Help.- Estas dos plataformas operan basado la modalidad de donaciones. La primera (Donaccion) busca proyectos relacionados con la niñez, para financiar proyectos solidarios. Help va dedicada a los estudiantes que por falta de recursos no culminaron sus estudios.

Como lo explica Callaghan (2014) la implementación de Crowdfunding, sin embargo, no está exenta de problemas y dificultades. Kickstarter ha tenido que hacer frente a los solicitantes fraudulentos (Wasik, 2012). Por lo tanto, el crowdfunding puede presentar riesgos para los inversores (Thompson, 2014; Wasik, 2012); los costos pueden ser impuestas a los inversores a través de la falta de conocimiento (Krasteva y Yildirim, 2013). Dentro de estas plataformas existen dos medios como los explica Martinez Cañas, Ruiz Palomino, \& Del Pozo Rubio (2012) mientras un proyecto cursa 40 días en dicho medio:

1. El proyecto está financiado con éxito y en consecuencia tarjeta de clientes se cargará cuando el proyecto llega a su fecha límite de financiación. También puede ser posible que un proyecto puede alcanzar su objetivo de financiación antes de la fecha límite lo que es mejor para el artista que se pueden mantener en la recaudación de fondos hasta que el período de 40 días ha terminado.

2. El proyecto no está financiado con éxito. La contribución de los clientes se cancela, la tarjeta no está cargada. En ese caso, los empresarios no pueden recibir el\% del dinero recaudado, porque para completar el proyecto que necesitan el 100\% que querían conseguir. Así que en esa situación es una buena cosa que repensar acerca de la idea, la descripción, el dinero es necesario, y las recompensas que se ofrecen a los clientes, los niveles de contribución y así sucesivamente.

\section{¿Existen riesgos al realizar crowdfunding?}

Un emprendedor debe tomar en consideración cuales son los riesgos que interviene al lleva a cabo esta modalidad de financiamiento Ruiz (s.f) mencionado 4 riesgos principales:

1. Riesgo operacional, cuando las plataformas tecnológicas usadas para obtener el capital necesario fallan y no protegen de forma adecuada la identidad de los inversionistas, la información relevante de la empresa o incluso el manejo del dinero recolectado, generando un riesgo potencial para los inversionistas de perder su dinero.

2. Riesgo en los registros, cuando las plataformas en las que se realizan las operaciones de inversión pueden no registrarse correctamente o atribuirse a procesos diferentes a los procesos a los que se tenía destinada dicha inversión.

3. Cumplimiento, si bien existen normas que regulan los procesos a llevar a cabo con el fin de tener una óptima divulgación de la información para el recaudo o del avance de los proyectos, ésta puede ser manipulada con el fin de incumplir acuerdos pactados entre el beneficiario, las plataformas y los acreedores.

4. Fraude, si bien los beneficiarios y los inversionistas deben revelar cierta información relacionada con las actividades de cada uno, existe el riesgo de fraude en el sentido que la entidad o grupo beneficiario no exista o que el recaudo de dinero se use para lavar dinero, robar a los inversionistas, entre otros. 


\section{Enterprise 2.0 o empresa 2.0}

Las herramientas 2.0 permiten mejorar la comunicación en la empresa tanto interna como externamente, dando lugar al concepto de empresa 2.0 (Ruiz del Castillo \& Luna Huertas, 2014).

La empresa 2.0 no se trata sólo de la aplicación de software social, pero describe un enfoque más amplio, que aboga por una nueva cultura de la participación, la inclusión y el compartir. (Chen Yun \& Jianbin, 2015)

Muñoz Aparicio, Perez Sanchez, \& Navarrete Torres (2016) expone que la utilización de la web 2.0 ofrece una serie de ventajas, tales como: el acceso e intercambio de información entre diversos usuarios conectados a la red; la promoción de la empresa y sus productos; mayor contacto con los clientes: ofreciendo la posibilidad de que las organizaciones publiciten sus productos, promuevan sus ventajas y se comuniquen con sus clientes localizados en diversas partes del mundo, a un costo mucho más bajo que si ocurriera en la forma tradicional y mucho más rápido, además de que permite la integración con proveedores.

Becerril, y otros (2012) opinan que las redes sociales surgieron como un fenómeno a partir del lanzamiento de Geocites, el cual fue creado en 1994 y su función era el alojamiento de páginas web de una determinada ciudad, donde cada habitante podía colocar su página web y poder colocar todo tipo de información que él quisiera, este autor explica que este sistema no es una red social como se las conoce en la actualidad, si provoco un gran cambio, ya que los usuarios perciben que no es difícil tener presencia en la red.

Existen organizaciones precursoras que han adoptado las herramientas y filosofías de la Red 2.0 para crear lo que se podría llamar "Empresa 2.0", lo cual no resulta natural o fácil a todas las empresas. Incluye Wikipedia, Facebook, Twitter entre otras (Muñoz Aparicio, Perez Sanchez, \& Navarrete Torres, 2016). Este tipo de empresa se caracterizan por el uso de estas herramientas que arrojaron el desarrollo de la web 2.0 para mejorar la comunicación de manera interna y externa mediante el uso de plataformas de software social dentro de la empresa, entre las mismas, socios y clientes.

McAfee (2006) citado por Ruiz y Luna (2014) en Muñoz Aparicio, Perez Sanchez, \& Navarrete Torres (2016) expone que: "La web 2.0 es diferente de las herramientas tradicionales debido a su adaptabilidad al entorno empresarial y a su rápida respuesta a las necesidades de cambios de las organizaciones."

La empresa 2.0, según Ruiz y Luna (2014) supone la composición necesaria de las tecnologías web 2.0 en sus procesos de negocio, intranet y extranet, entendiendo el desarrollo de nuevos canales de comunicación bidireccionales a través de las herramientas 2.0, entre los diferentes departamentos e individuos que conforman la organización como entre la empresa y sus diferentes agentes: empleados, accionistas, socios, clientes, proveedores y otros. (Muñoz Aparicio, Perez Sanchez, \& Navarrete Torres, 2016).

Chen Yun \& Jianbin (2015) exponen que las empresas están aprovechando estos sitios para algo más que comunicar. A través de las zonas Web 2.0 y redes sociales, las empresas están intercambiando los medios de comunicación, compartir documentos, distribuir y recibir hojas de 
vida, desarrollar y compartir aplicaciones personalizadas, aprovechar las soluciones de código abierto, y proporcionando foros para clientes y socios.

Según Mares (2015) citado en Muñoz Aparicio, Perez Sanchez, \& Navarrete Torres (2016) opina que todos los sectores van a migrar a las redes sociales de manera gradual, aunque no necesariamente se valdrán de las ofertas comerciales y publicitarias para alcanzar visibilidad. De acuerdo con cálculos de Google, actualmente, por cada 10 mil usuarios, sólo 4 de ellos dan click en los anuncios. Sin embargo, según comScore, 1 de cada 4 anuncios gráficos que se miran en la red han sido visualizados en Facebook. Esta red social se acerca a los mil millones de usuarios registrados (600 millones de ellos son visitantes frecuentes). En este sentido las empresas apuestan a estos nuevos prosumers, pues son ellos quienes eligen lo que quieren ver y comprar. Por su parte, Twitter, con 175 millones de usuarios registrados (100 millones activos), es utilizada mayoritariamente por el denominado círculo rojo, destinado a formar y crear una tendencia de opinión.

Como lo explica H \& S (2014) los beneficios que conllevan estos medios es vital tomar en consideración, como positivos tenemos:

- Marketing.- Gracias a los medios sociales se está logrando comercializar métodos que comparados a los del marketing tradicional son más eficientes y baratos e incluso gratis en algunos casos. Visto desde un punto comercial estas crean una relación de ganar-ganar en la publicidad y comercialización de nuevos medios de comunicación.

- Ajuste de negocios y comentarios del cliente.- gracias a la ayuda que nos dan los medios sociales se pueden discutir problemas y preocupaciones de manera virtual y llegar a tomar decisiones a nivel de negocios

A si hay beneficios también hay inconvenientes con las redes sociales, entre las cuales se destacan:

- Autenticidad de información engañosa. - Al ser un medio que la mayoría de la gente usa, al emitir una información sea esta sin editar, sin restricciones se puede llegar hacer conmoción de una noticia que en totalidad puede ser falsa.

- Estafas, Spam y virus.- Los hacker puede enviar materiales nocivos en las que se incluyen mensajes o videos que contengan virus con el fin de conocer información clasificada y venderla al mejor postor. Según (Gewirtz, 2009 citado por H \& S, 2014) da a conocer que: "Una cuarta parte de las empresas han sido víctima de spam, phishing o ataques de malware a través de sitios como Twitter, Facebook LinkedIn y MySpace".

\section{Estrategias 2.0}

La presencia de una empresa, un producto o una marca en medios sociales no tiene sentido alguno, por lo que sólo entendiendo las plataformas 2.0 no sólo como meros canales de comercialización, sino sobre todo como espacios de conversación, se podrá llevar a cabo una estrategia y un plan de medios eficaces (Castelló Martínez , 2014).

La estrategia 2.0 de contenidos se convierte en la pieza fundamental, ya que busca atraer clientes potenciales generando confianza y credibilidad y posicionando a la empresa como experta en su sector de actividad. (Castelló Martínez , 2014). Esto se logra con comunicación de calidad con el marketing de atracción 2.0 se fundamenta en cuatro acciones que se estudian en la 
ponencia presentada y se desarrollan estratégicamente en este orden al menos inicialmente: crear, optimizar, promocionar y convertir-analizar. (Castelló Martínez , 2014).

Lo que se quiere lograr es ofertar productos y servicios acordes al usuario, sin llenarlo de publicidad que lejos está de captar su atención y lo que probablemente consiga es cansarlo ocasionando un rechazo hacia ese producto o servicio esto es posible mediante:

- Marketing 2,0 se define como el uso de la tecnología Web 2.0 y las capacidades interactivas que ofrece para el propósito de abrir los canales de comunicación interactivos entre consumidores y empresas (Bach, 2013)

- Really Simple Syndication (RSS) es un formato para la entrega de contenido Web que cambia regularmente. Muchos sitios newsrelated, weblogs y otros editores en línea, organizan su contenido como una fuente RSS a quienes lo requieran. RSS lleva los últimos titulares de diferentes sitios Web, y empuja a los titulares a su equipo para la exploración rápida. RSS sobre todo utiliza XML para entregar el contenido actualizado en la web. (Geetha \& Bharathi, 2013) Simplemente es un programa de complemento de navegador diseñado para recoger y mostrar los canales RSS de acuerdo con los parámetros definidos por el usuario. Un lector de RSS puede reducir el tiempo y el esfuerzo necesarios para comprobar las publicaciones en línea para las actualizaciones. (Geetha \& Bharathi, 2013)

- El etiquetado permite tener presentes los ítems sin que físicamente se encuentren visibles, sólo se ven sus nombres. Al conocer cuántos ítems hay se tiene una idea del consumo de espacio físico en la web, así como del espacio cognitivo (por así decirlo) en el cerebro del usuario. (Pérez Montoro, 2015) Lo que genera el uso de etiquetas permite no tener que ofrecer simultánea y literalmente todos los contenidos en el mismo nivel o espacio, consiguiéndose aligerar visualmente la página web. (Pérez Montoro, 2015)

- El generar contenidos audiovisual está a la orden del día y es un recurso que debe ser empleado por las empresas para generar compromiso con los consumidores y otros grupos de interés, muestra de ello es el crecimiento que han experimentado redes sociales como YouTube, Pinterest o Instagram en los últimos años. (Pérez Shampol, Gomez Zorrilla Amate, \& Marco Blanco, 2015)

- Mercadeo viral es la comercialización de boca en boca se usa en relación a una marca, producto o servicio similar, a la propagación viral en las redes sociales o sobre medios electrónicos (Akyol, 2013) en palabras más simple es la opinión del consumir expuesta en la web 2.0

\section{Efectos de la Web 2.0 a nivel de emprendimiento Positivos}

- El Observatorio de Divulgación Financiera (2014) establece que: "La aparición del CF coincide con la grave crisis económica mundial como una forma de buscar modelos de financiación alternativos a los tradicionales."

- Inicio al desarrollo de una nueva terminología denominada crowdfunding, frecuentemente traducido como "financiación en masa o colectiva", describe un amplio y variado fenómeno consistente en la creación de un entorno (electrónico) para la agrupación de un colectivo, la aportación de ideas, recursos y fondos y la interacción en red dirigidas a apoyar conjuntamente proyectos, esfuerzos e iniciativas de individuos, organizaciones o empresas. (Rodriguez de las Heras Ballell, 2013) 
- Valanciene y Jeg Eleviciute (2013) citado por Estarellas Gardiol (2015) expresa que el funcionamiento del crowdfunding por defecto otorga al emprendedor la oportunidad de visualizar si su productos o servicio que va a ofrecer va a tener acogida en el mercado establecido, ya que el mecanismo que se basa esta modalidad es atraer a un gran número de individuos que si consideran interesante apostaran por él.

- Estarellas Gardiol (2015) establece que: "El crowdfunding genera una importante oportunidad en la economía, ya que fomenta el autoempleo y crea puestos de trabajo".

- Mediante las herramientas 2.0 el usuario puede enterarse del producto o servicio que se ofrece gracias a la posibilidad de crear orden desde el caos, por el sistema de etiquetado, los canales RSS y los agregadores automatizados. (Ruiz del Castillo \& Luna Huertas, 2014)

\section{Negativo}

- Para poder atraer inversores para su idea, el empresario deberá exponer su idea en una plataforma de crowdfunding y transmitir información acerca del proyecto. Couffinhal (2014) y Valanciene y Jegeleviciute (2013) advierten del riesgo de que la idea sea robada por parte de emprendedores mejor financiados o grandes corporaciones si el proyecto no está correctamente protegido. (Estarellas Gardiol, 2015)

- "En relación con lo anteriormente expuesto, la exposición pública de un proyecto empresarial en Internet genera una alta visibilidad que puede actuar de manera negativa para el empresario, creando una mala imagen en caso de fracaso del proyecto." (Estarellas Gardiol, 2015).

- “Al tratarse de un método de financiación relativamente reciente, la legislación existente sobre el crowdfunding es escasa o nula. El aumento del número de proyectos, así como de plataformas, puede poner en peligro el futuro del crowdfunding. (Estarellas Gardiol, 2015)”.

\section{Efectos de la web 2.0 a nivel empresarial Positivos}

- (Leal, 2007 citado en (Muñoz Aparicio, Perez Sanchez, \& Navarrete Torres, 2016) establece que:

- La utilización de la web 2.0 ofrece una serie de ventajas, tales como: el acceso e intercambio de información entre diversos usuarios conectados a la red; la promoción de la empresa y sus productos; mayor contacto con los clientes: ofreciendo la posibilidad de que las organizaciones publiciten sus productos, promuevan sus ventajas y se comuniquen con sus clientes localizados en diversas partes del mundo, a un costo mucho más bajo que si ocurriera en la forma tradicional y mucho más rápido, además de que permite la integración con proveedores.

- Almedia (2012) afirma que: Por ello las empresas están aprovechando estos sitios para algo más que comunicar. A través de las zonas Web 2.0 y redes sociales, las empresas están intercambiando los medios de comunicación, compartir documentos, distribuir y recibir hojas de vida, desarrollar y compartir aplicaciones personalizadas, aprovechar las soluciones de código abierto, y proporcionando foros para clientes y socios.

- "Para cualquier empresa las comunidades virtuales o redes sociales virtuales (en adelante $\mathrm{RSV}$ ) son una herramienta esencial y una oportunidad para generar imagen de marca y 
convertir seguidores en clientes." (Garcia Muñoz Aparicio, Perez Sanchez, \& Navarrete Torres, 2016).

\section{Negativos}

- Almeida (2012) define: Mientras todo esto interactividad es emocionante y motivador, hay una triple amenaza que se encuentra en la Web 2.0: las pérdidas de la productividad, la vulnerabilidad a las fugas de datos, y el aumento de los riesgos de seguridad inherentes.

- Almeida (2012) da a conocer lo siguiente: Hay dos consecuencias reales y percibidas de inapropiada la Web 2.0 y las redes sociales uso:

- La consecuencia financiera para los incidentes de seguridad (incluyendo el tiempo de inactividad, la información y la pérdida de ingresos).

- El uso inadecuado de los medios sociales pueden reputación de la empresa pérdida, marca o cliente de confianza.

- Inversiones adicionales no planificadas necesarias para la aplicación de los medios de comunicación social en sus organizaciones;

- Litigios de amenazas legales causadas por empleados que dan a conocer información confidencial o sensible.

- Almeida (2012) define una vulnerabilidad que ocurre en la web 2.0 y la define como: "Uno de los problemas de seguridad más peligrosos y preocupantes en la Web. En este ataque, dos capas aparecen en un sitio, uno visible, uno transparente, y los usuarios sin darse cuenta interactúan con la transparencia capa en ese tiene una intención maliciosa."

\section{Ejemplo de éxito de un proyecto ecuatoriano en una plataforma Crowdfunding}

Se ve la relevancia que han desarrollado estas plataformas, un claro ejemplo es el proyecto explicado en Oficina Comercial del Ecuador en Chicago (2014): En el mes de noviembre de 2014, la empresa estadounidense Allegory, con el apoyo de PROECUADOR y la Oficina Comercial de Ecuador en Chicago, lanzó el proyecto del bolso de makana en la plataforma Kickstarter. Allegory, junto con artesanos de makana de la provincia de Azuay y artesanos de cuero de la provincia de Cotopaxi, crearon un bolso de cuero con un forro interno de makana para ser vendido en los EE.UU.

- Luego de los 45 días de debut en la página Kickstarter, el proyecto sobrepasó su meta de USD 30.000, logrando un total de USD \$31.160 para financiar el proyecto y comenzar la producción de este bolso en Ecuador. Artesanos de la makana como José Jiménez, de la localidad de Gualaceo, se verán beneficiados con este proyecto al ser parte de su cadena productiva. El bolso será comercializado en EE.UU. durante el primer semestre del 2015, apoyando las exportaciones de artesanos ecuatorianos que fabrican este producto de alta calidad. Allegory se ha comprometido también en reinvertir parte de sus ganancias en impulsar nuevos productos de artesanos ecuatorianos, al igual que en expandir la producción del bolso de makana.

\section{Conclusión}

Resulta ser evidente que la web 2.0 ha traído consigo muchos factores positivos como negativos en especial para el sector de emprendimientos, entre los efectos generados por la web 2.0 esta que ofrece una alternativa de financiamiento diferente a la tradicional mediante 
plataformas digitales (Crowdfunding) la que por medio de sus cuatro categorías que son recompensa, donación, Crowdequity, Crowdlending ofrece una nueva oportunidad a los emprendedores para obtener recursos y no solo financiero si no también con socios estratégicos por medio (crowdsourcing) el mismo que mediante una plataforma digital hace un llamado a mejorar un determinado producto o servicio a una persona o empresa, por lo tanto al momento que se decida elegir este modo de financiamiento se debe elegir qué tipo de crowd se va a usar para el proyectos, siempre tomando en consideración la plataforma a usar de todas las que existen en el medio y los riesgos que estos conllevan.

Indiscutiblemente la evolución que ha tenido web ha cambiado el mundo otorgando todas estas herramientas, que ayudan al sector de emprendimientos y no solo eso ya que posterior al desarrollo del mismo se puede llegar a convertir en una empresa, si se usa todas las herramientas que ofrece la web 2.0 a nivel empresarial se puede convertir en la Enterprise 2.0, todo este conjunto de variables hace que los emprendimientos tenga una posibilidad mayor de llevarse a cabo aunque no se debe omitir los efectos que también conllevan en especial los negativos del sector de emprendimiento y empresarial entre los de mayor importancia se encuentra la fuga de información y el plagio. El proyecto expuesto anteriormente es un claro ejemplo para los emprendedores en aprovechar estas plataformas para financiar sus ideas de negocios para luego llevarlas a otro nivel.

Akyol, E. (2013). Social Media and Marketing: Viral Marketing. Academic Journal of Interdisciplinary Studies, 586-590.

Alarcon del Amo, M., Romero, C., Gomez Borja, M., \& Mondéjar Jiménez, J. (2012). Web 2.0 tools in retailing: Benefits of their use ans Reasons for not using them. International Businees \& Economics Reseach Journal, 1463-1470.

Almedia, F. (2012). Web 2.0 Technologies and Social Networking Security Fears in Enterprises. IJACSA (Revista Internacional de Informatica Avanzada y Aplicaciones) Vol 3. No. 2, $152-$ 156.

B. Bouncken, R., Komorek Lappeenranta, M., \& Kraus, S. (2015). Crowdfunding: The current state of research. International Business \& Economics Research Journal, 407-416.

Bach, C. (2013). How to Implement Marketing 2.0 Successfully. International Journal of Business and Social Science, 36-42.

Becerril, J., Vallejo , A., Lumbreras, A., Chavez Ojeda, G., Duk, A., \& Torres, R. (03 de 12 de 2012). La web 2.0: Un analisis de su impacto en lo social, politico, cultural y economico. Investigacion Universitaria Multidisciplinaria, 22-34.

Callaghan, C. (2014). Crowdfunding to Generate Crowdsourced R\&D: The alternative parading of societal problem solving offered by second generation innovation and R\&D. International Business \& Economics Reseach Journal, 1499-1514.

Castelló Martínez , A. (2014). La estrategia de medios sociales, el Inbound Marketing y la estrategia de contenidos:. Eje temático: Nuevas estrategias de persuasión en la Red: marketing y publicidad online, 1-25.

Chen Yun, X., \& Jianbin. (2015). A Self-organization Analysis of Knowledge Collaboration with Enterprise 2.0 Application. Revista internacional de Servicio $U$ y electronico, Ciencia y Tecnologia, 1-10.

Consoli, D. (2012). A collaborative platform to support the Enterprise 2.0 in activie interactions with customers. Informatica Economica, 37-49. 
Estarellas Gardiol, K. (2015). Crowdfunding, una nueva alternativa de financiacion en auge. Universidad de LA Laguna. Facultad de Economia, Empresa y Turismo, 1-34.

Estevez, J., \& Garcia , A. (2014). Las redes sociales para la mejora de la capacidad de emprender y de autoempleo. International Journal Of Education Research and Innovation, 101-110.

Flores, J., Bertolotti, C., \& Gonzalez, F. (2012). La web 2.0 y la herramienta de colaboracion y participacion. Universidad de San Martin de Porres. Universidad Politecnica de Valencia, 4.

Galmes, M., \& Borja Arjona, J. (2012). Crowdsourcing: La base social como fuente de creatividad en contestos de crisis. Creatividad y sociedad, 1-29.

Geetha, A., \& Bharathi, S. (2013). Rss feeds and news content categorization. Revista Internacional de Avances recientes en Ingeniería y Tecnología, 51-57.

Gomez de la Rosa, V. (2015). ¿Como el Crowdfunding puede impulsar el emprendimiento, la innovacion y transformacion la banca tradicional en Colombia? Universidad EAFIT. Escuela de administracion, 1-72.

H, A., \& S, W. (2014). Adoption Of Social Networks In Business: Study Of Users And Potential. International Business \& Economics Research Journal, 401-418.

Martinez Cañas, R., Ruiz Palomino, P., \& Del Pozo Rubio, R. (2012). Crowdfunding ans social networks in the musical industry: Implications for Entrepreneurship. International Business \& Economics Research Journal, 1471-1476.

Muñoz Aparicio, C., Perez Sanchez, B., \& Navarrete Torres, M. (2016). Las redes sociales y el desarrollo de las mipymes. Ciencia desde el Occidente , 75-84.

Njegomirl, V., Tepavac, R., \& Ivanisevic, N. (2017). Alternative sources of financing entrepreneurial undertakings in agriculture. Economics of Agriculture, 295-306.

Oficina Comercial del Ecuador en Chicago. (2014). Crowdfunding y la plataforma web de busqueda de fondos Kickstarter. Chicago.

Oh, S., \& Baek, H. (2016). Successful crowdfunding: Focusing on Social Interaction And Goal Achievement Motivations. Tecnologias en Sistemas de Investigacion, 141-161.

Pérez Montoro, M. (2015). Arquitectura de la información en entornos web. Baratz, 333-337.

Pérez Shampol, C., Gomez Zorrilla Amate, J., \& Marco Blanco, J. (2015). La comunicación empresarial en la web 2.0 estrategias para la comunicacion efectiva de la reputación corporativa. Tecnologia ciencia y eduación, 62-67.

Pilar, T. (2014). Crowequity y crowdlending: ¿Fuentes de financiacion con futuro? Observacion de Divulgacion Financiera, 1-29.

Ramirez Herrera, L., \& Muñoz Campano, S. (2016). El Crowdlending como nueva herramienta de financiación. Analisis Financiero, 40-56.

Rodriguez De Las Heras Ballel, T. (2013). el Crowfunding; una forma de financiacion colectiva, colaborativa y participativa de proyectos. Revista 3ra Edicion Pensar en Derechos, 110-123.

Rodriguez Diaz, R., \& Gonzalez Rio, M. (09 de 05 de 2016). La web 2.0 herramienta de empoderamiento de las empresas Pymes. Un estudio de caso en el contexto Andaluz. Feminismo/s, 2019-242.

Ruiz del Castillo, J. C., \& Luna Huertas, P. (2014). La Web 2.0 en el entorno empresarial: socializando a las PYMES. Pixel-Bit. Revista de Medios y Educación, 65-77.

Ruiz, J. (s.f.). De la mano del crowfunding. UAMF (Unidad de Analiis de Mercado Financiero), 7.

Schaefer, D., \& Forbes, H. (2017). Guidelines for successful crowdfunding. El Sevier, 398-403. 